sections of their communities with the lower ranges of income, and particularly to ensure an adequate supply of safe milk for expectant and nursing mothers, infants, children and adolescents. Further recommendations include the examination of schemes to make supplies of the protective foods available at prices within the reach of all classes without prejudicing the interests of producers. If necessary, the question of the re-orientation of agricultural production, with the view of satisfying the requirements of sound nutrition, should be seriously considered.

\title{
Malaria and Nutrition
}

$\mathrm{T}$ HE Royal Society, more than thirty-five years ago, followed up Ross's discovery of the mosquito-cycle of the malaria parasite by sending specially qualified research workers to Africa and India to study the endemiology and epidemiology of the disease and the life-history and habits of the mosquitoes which transmit it. Judged by the results of those investigations, which were published as Reports to the Malaria Committee of the Society between 1899 and 1903, the action was one of the most important steps ever taken for the advancement of knowledge of the subject. The Society has recently taken a second step which everyone will hope may have an equally important outcome. At a meeting held in July this year, the Council decided that the whole income, together with the invested income, of its Medical Research (Anonymous) Fund should be employed for a period of five years on a scheme of laboratory research on malaria to be conducted in England, and a field inquiry into malnutrition to be conducted in India. The two subjects are more closely related than may be apparent, for it has been shown repeatedly in Italy and elsewhere that measures designed to improve the nourishment and general welfare of the people have a great effect in lessening the mortality, disability, and other evils due to acute or chronic malarial infection.

The scheme as a whole is estimated to cost about $\mathfrak{1}, 500$ for the period mentioned, and has been worked out and arranged for in detail. The malaria programme is in two parts, of which the first is concerned with the parasites and their relationship with human, animal and insect hosts, the second with the ecology of one or more of the species of anopheline mosquitoes chiefly responsible for spreading malaria in the tropics. On both subjects an advanced type of scientific 'long-range' research by modern experimental methods is contemplated. It is believed that in the present state of knowledge this highly specialized type of work offers the best hope of improving existing methods of dealing with malaria, and it is recognized that its pursuit has been facilitated during recent years by several outstanding events such as the application of the practice of malariatherapy to the study of malaria itself, as well as for its original purpose, and the discovery that monkeys, as well as canaries and other birds, can be utilized for studying immunological and other problems. It is intended, too, to give increased attention to the chemotherapy of malaria, which has become of paramount importance since the discovery of effective synthetic anti-malarial remedies, and is a subject on which, up to the present, little has been done in Great Britain (see Nature, Nov. 9, 1935, p. 743).

The practical object of the proposed research into the ecology of a particular species of anopheline mosquito is to improve the antimalarial method called 'species sanitation', which aims at the elimination from an area of the species that has been found to be most concerned in transmitting the disease. Success in this task would be greatly facilitated if complete knowledge were available of the biology, habits and behaviour of the insect concerned, and particularly if the physical, chemical and other factors governing its choice of breeding places, food supply, shelter and other items of behaviour were precisely known. Thanks to new methods devised by insect physiologists, these problems can now be studied experimentally in the laboratory and applied to observations made in the field.

Lieut.-Col. J. A. Sinton, I.M.S., lately director of the Malaria Survey of India, has been appointed to conduct the first part of the malaria programme, and it has been arranged that he will work in the laboratories of the Malariatherapy Centre at Horton where, in addition to the intensive study of particular problems, he will have an opportunity of continuing and extending the observations on 
induced malaria which it was feared might have to be given up when Colonel S. P. James retires this year.

The second part of the programme is to be commenced in the Entomological Department of the London School of Hygiene and Tropical Medicine by the appointment of a young worker with experience in modern experimental zoology. For a period of 12-18 months he will study the physiology and behaviour of the several species of anopheline mosquitoes which can be made available in England, and will then proceed to an appropriate centre in India for the special research proposed. It is understood that the London School has undertaken to meet part of the cost of this research.

Dr. Curjel Wilson has been appointed to conduct the nutritional survey in India in collaboration with Dr. Aykroyd, director of nutrition research to the Indian Research Fund Association. The survey will be concerned chiefly with the incidence of malnutrition among school children, and the dietary habits of groups of families in the districts where the children live. An important object of the investigation will be to train workers who will continue and extend the survey.

It may confidently be expected that the expenditure from its trust funds by the Royal Society which this programme involves will be fully justified by the additions it will make to our knowledge of malaria, which, despite all that has been done during the last three decades, still remains the greatest single destroyer of the human race.

\section{Nature and Purpose of Science}

The Scientist in Action:

a Scientific Study of his Methods. By Dr. William H. George. Pp. 355. (London: Williams and Norgate, Ltd., 1936.) 10s. $6 d$. net.

$\mathrm{T}$ HE reviewer's first task is to state the nature of the book and the purpose of its author. Here this task is very difficult. "Action" is the keyword of the title; and on his first page, Dr. George tells us that he takes it "as basic that scientific research is a form of human action". But he has just said that "by definition speaking, writing or manipulation . . . are forms of action but thinking, believing or feeling are not." Research then, for Dr. George, is an activity in which thought and belief play no part. This is sufficiently puzzling; but it becomes more puzzling when most of the book is found to be concerned with things that are indubitably thought or believed and not done-laws, theories, propositions in general, and so forth.

This inconsistency pervades the book. A possible (but of course speculative) explanation is suggested by hints in the final section. It is that Dr. George started to "clarify his mind on the relation between experiment and theory, and more especially on the relation between experimental and mathematical physics"-in other words, to solve the central problem of the philosophy of science. Reading the works of his forerunners, he was repelled (as many others have been) by the folly of those to seek to interpret science as a set of formal propositions out of any relation to the scientists who produce them. He therefore rushed to the other extreme and, "to his own surprise", arrived at the conclusion that science, though "inseparable from scientists, is quite separate from philosophy". In order to understand science, all that is necessary is to study the scientist reacting, like any other organism, to its environment; his problem turned out to be purely biological.

Of course, Dr. George could not act consistently on such a belief. Mental activity is even more difficult than physical activity to describe without some preconceived scheme to which it is supposed to conform; and even if a perfectly neutral description of the mental activity of a scientist could be given, it would not explain that activity or clarify anyone's mind concerning it. For that task it is necessary to show that the activity does conform to some logical scheme that is equally valid for all kinds of thought; the ordering of different kinds of thought into a single coherent whole is not merely inseparable from philosophy ; it actually is philosophy. Accordingly, Dr. George found himself alternating between his new desire to ignore all forms of activity that cannot be merely described, and his old desire to clarify his mind; his book is a queer medley of his two moods.

Dr. George's work in his old mood does not appear to me very valuable. He has made the common mistake of being so preoccupied with those at the opposite extreme of thought as to ignore altogether those who stand very near to his own point of view. Thus, he might have been expected to find Bridgman's "operational" 